\title{
Threshold Size of Medical Tablets and Capsules: Based on Information Collected by Japanese Medical Wholesaler
}

This article was published in the following Dove Press journal: Patient Preference and Adherence

\author{
Kenji Kabeya' \\ Hiroki Satoh (iD) 2,3 \\ Satoko Hori ${ }^{4}$ \\ Yasumasa Miura ${ }^{5}$ \\ Yasufumi Sawada ${ }^{2}$ \\ 'Faculty of Pharmaceutical Sciences, The \\ University of Tokyo, Tokyo II3-0033, \\ Japan; ${ }^{2}$ Laboratory of Drug Lifetime \\ Management, Graduate School of \\ Pharmaceutical Sciences, The University \\ of Tokyo, Tokyo II3-0033, Japan; \\ ${ }^{3}$ Interfaculty Initiative in Information \\ Studies, The University of Tokyo, Tokyo \\ I 13-0033, Japan; ${ }^{4}$ Laboratory of Drug \\ Informatics, Keio University Faculty of \\ Pharmacy, Tokyo 105-85I2, Japan; ${ }^{5}$ Toho \\ Holdings Co., Ltd, Tokyo I55-8655, Japan
}

Correspondence: Yasufumi Sawada Laboratory of Drug Lifetime Management. Graduate School of Pharmaceutical Sciences, The University of Tokyo, 7-3-I Hongo, Bunkyo-Ku, Tokyo II 3-0033, Japan

Tel +8I $3584 I 1096$

$\mathrm{Fax}+8 I 3584 I 1097$

Email sawada@mol.f.u-tokyo.ac.jp
Background: Medical tablets and capsules are superior with regard to portability and are the most common dosage form in Japan. However, their large size often results in difficulties during ingestion, sometimes leading to reduced medication adherence.

Objective: The authors used postmarketing surveillance data to determine the threshold size of medical tablets and capsules that patients feel are too large to ingest.

Patients and Methods: The marketing specialists of Toho Pharmaceutical Co., Ltd. collected opinions of patients and medical workers (November 2014-April 2016). Regarding 709 reports from patients stating that the tablet or capsule for too large for ingestion, a dataset was prepared from package inserts of the reported drugs. Two analyses were conducted: histogram analysis of size distribution and geometric analysis using linear approximation. Six indices of tablet/capsule size were considered: length; length + width; length + width + depth; length $\times$ width; length $\times$ width $\times$ depth; and weight.

Results: Histogram analysis revealed that length + width + depth is an excellent index of tablet/capsule size, and negative reports on tablet/capsule size drastically increase when this index is $\geq 21 \mathrm{~mm}$. Geometric analysis using linear approximation also revealed similar results.

Conclusion: The threshold size of tablets/capsules that patients feel are too large to ingest is length + width + depth $=21 \mathrm{~mm}$. Therefore, when designing or altering tablets/capsules, if length + width + depth is $\geq 21 \mathrm{~mm}$, the drug should be scored, split into smaller doses, or redesigned as an orally disintegrating formulation.

Keywords: marketing specialist, size, shape, tablet, capsule, postmarketing surveillance

\section{Introduction}

Compared with other drug forms, medical tablets and capsules are more superior with regard to portability and are the most common dosage form in Japan. However, the large size of some medical tablets/capsules makes it difficult to ingest them, causing discomfort to patients and sometimes leading to a decline in medication adherence. ${ }^{1,2}$

To solve this problem, the global pharmaceutical industry should have knowledge regarding the size of medical tablets and capsules that is appropriate for patients. Several studies have investigated the shapes and sizes of medical tablets and capsules. $^{3-13}$ For example, Oshima et al suggested that tablets with a diameter greater than $7 \mathrm{~mm}$ are hard to ingest for elderly people. ${ }^{7}$ Hashimoto concluded that diameter of $7 \mathrm{~mm}$ is the most appropriate for elderly people to ingest. ${ }^{10}$ However, 
these studies had the following limitations: (i) most were small clinical studies involving healthy volunteers and did not reflect the evaluation and tolerance of real patients, (ii) most only investigated the diameter of round tablets and did not consider the three-dimensional shape of tablets, and (iii) the studies only compared patient preferences using different tablet/capsule sizes and did not focus on the appropriate size range or threshold size and, therefore, did not reveal information useful for drug formulation design and development.

In Japan, medical representatives (MRs) of pharmaceutical companies conduct postmarketing surveillance (ie, the collection of pharmaceutical information from clinical fields). However, MRs are generally the employees of pharmaceutical companies and are responsible for promoting their companies' products; therefore, this system of data collection has some limitations regarding its effectiveness: (i) MRs cannot collect information about other companies' products and (ii) MRs need to focus on communicating with doctors and thus get few opportunities to visit community pharmacies (especially in countryside) to assess pharmacists' opinions. ${ }^{14}$

Conversely, in Japanese medical logistics, medical wholesalers act as brokers between pharmaceutical companies and medical institutions for an effective and stable supply of medicines. These medical wholesalers stock medicines from pharmaceutical companies, and some of their employees [so-called marketing specialists (MSs)] deliver ordered medicines to medical institutions on a daily basis. MSs deal in medicines from different pharmaceutical companies and frequently visit medical institutions; therefore, they can overcome the limitations of the current system for postmarketing information collection.

In November 2014, Toho Pharmaceutical Co., Ltd., Tokyo, Japan (one of the big4 medical wholesalers in Japan) developed a postmarketing surveillance system called "Postmarketing Event Monitoring Marketing Specialists" (PEM-MS). Since its inception, the PEMMS system has been collecting and storing approximately 400 reports every week. Most of these reports include problems regarding medical tablets and capsules or their packaging. ${ }^{15}$ Some medical wholesalers have made similar postmarketing surveillance efforts; ${ }^{16,17}$ however, none of their efforts managed to generalize the collected information and to obtain useful knowledge from it.
The aims of this study are: (i) consider the threedimensional threshold size of medical tablets and capsules from the collected clinical opinions and (ii) create pharmaceutical knowledge for drug formulation design and development from the information collected by MSs.

\section{Patients and Methods Analyzed Data}

Data for this study were retrospectively acquired from Toho Pharmaceutical, which stores opinions and requests related to medical tablets and capsules and their packages received by the company's MSs during their visits to medical institutions, such as hospitals and pharmacies. In all, 17,533 reports were collected from Tokyo region during November 2014-April 2016; these reports included the date of data collection, the profession of the medical worker, the name of the product, the nature of the product (such as formulation or package), and details of the medical worker's opinion or request. The data did not include any confidential or personal information, and ethical approval for this study by the Ethics Committee of the University of Tokyo was not required.

Of these 17,533 reports, 709 were included for analysis based on the following two inclusion criteria: the opinions or requests stating that (i) the medical tablet/capsule was too large and (ii) the medical tablet/capsule size annoyed patients, not medical workers. In addition, only the upper threshold size of medical tablets/capsules for patients was considered. There were only 89 reports stating that the medical tablet/capsule was too small for patients, and these reports were not considered owing to insufficient data.

\section{Indices of Drug Size}

The authors attempted to make the elemental indices of tablet/capsule size in order to simplify their consideration during drug formulation design and development. The authors considered the following six indices of tablet/capsule size: (i) length, (ii) length + width, (iii) length + width + depth, (iv) length $\times$ width, (v) length $\times$ width $\times$ depth, and (vi) weight (Figure 1).

These indices were calculated using the data present in package inserts of reported medical tablets/capsules. For round medical tablets, both the length and width were considered as the diameter. For medical capsules, both the width and depth were considered as the diameter. 

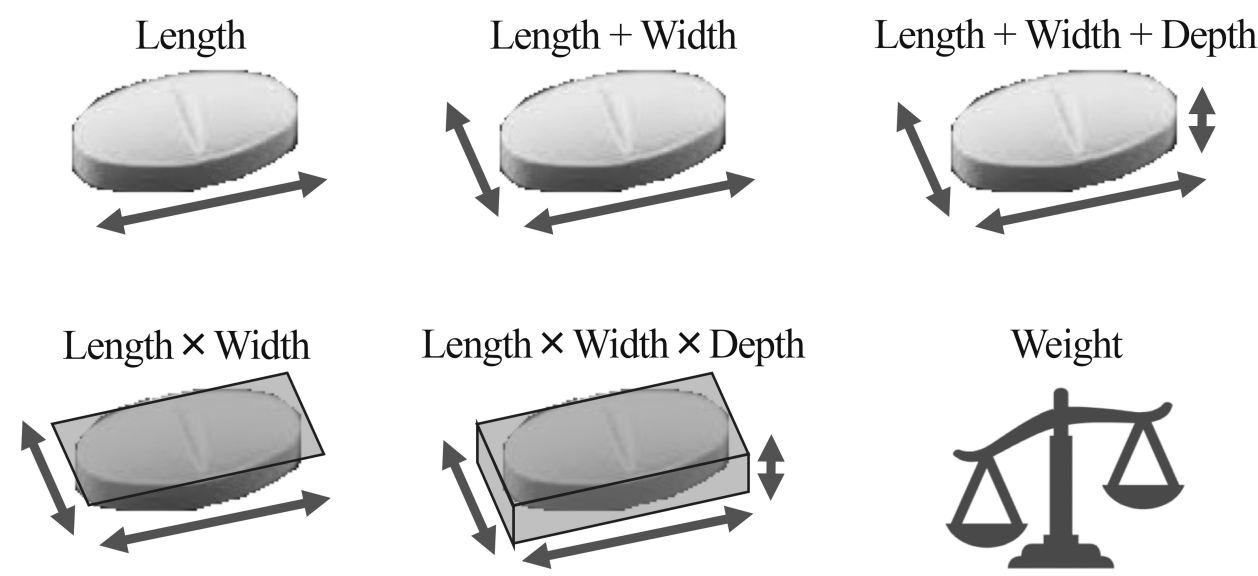

Figure I Indices of the size of medical tablets and capsules. The following six indices of medical tablet/capsule size were considered: (i) length, (ii) length + width, (iii) length + width + depth, (iv) length $\times$ width, $(v)$ length $\times$ width $\times$ depth, and (vi) weight.

Using the aforementioned six indices, two analyses were performed: analysis of histograms of size distribution and geometric analysis using linear approximation.

\section{Analysis of Histograms}

Histograms were generated using the aforementioned six indices. The $x$ axes represented the scores of the indices and the $\mathrm{y}$ axes represented the number of reports. With regard to the threshold size of medical tablets/capsules, it was desirable for the histogram to show a drastic increase in the number of reports above a specific index score ( $I$; Figure 2); this score identifying the drastic increase can be considered as the threshold size of medical tablets/capsules. Using the six histograms, we selected one index that the authors considered appropriate in order to estimate the threshold size of medical tablets/capsules and additionally performed an analysis.

\section{Geometric Analysis with Linear Approximation}

The selected index was subjected to geometric analysis with linear approximation using Microsoft Excel 2016 ver. 1803 (Microsoft Corporation, WA, USA).

First, instead of a histogram, a continuous graph of the accumulated number of reports was plotted (Figure 3). The $x$ axis represented the sum of the length, width, and depth of the medical tablets/capsules $(0.1-\mathrm{mm}$ increments, similar to the original data), and the $y$ axis represented the accumulated number of reports. Because the bins of the histograms were constructed using 1-mm increments, there was a possibility of a distortion in histogram analysis. However, this problem was avoided using the continuous graph. In this graph, the bending point represented the point where the frequency of the reports drastically changed and, thus, was considered the threshold score and was calculated in the following manner (Figure 4):

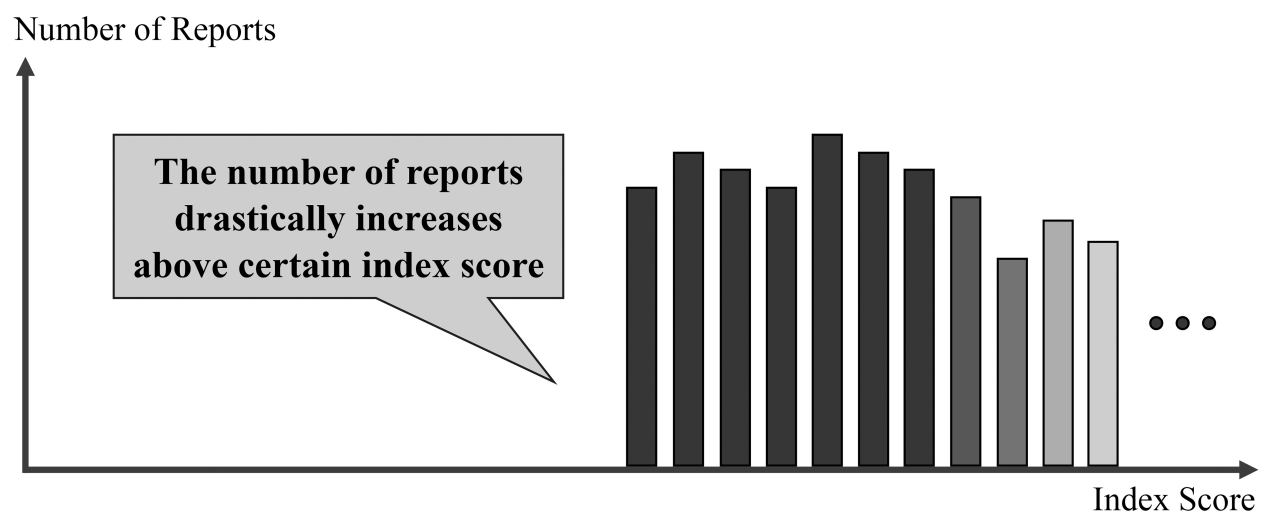

Figure 2 Histogram of the index score ( $x$ axis) versus the number of reports ( $y$ axis) for determining the ideal index for determining the size of medical tablets and capsules. 


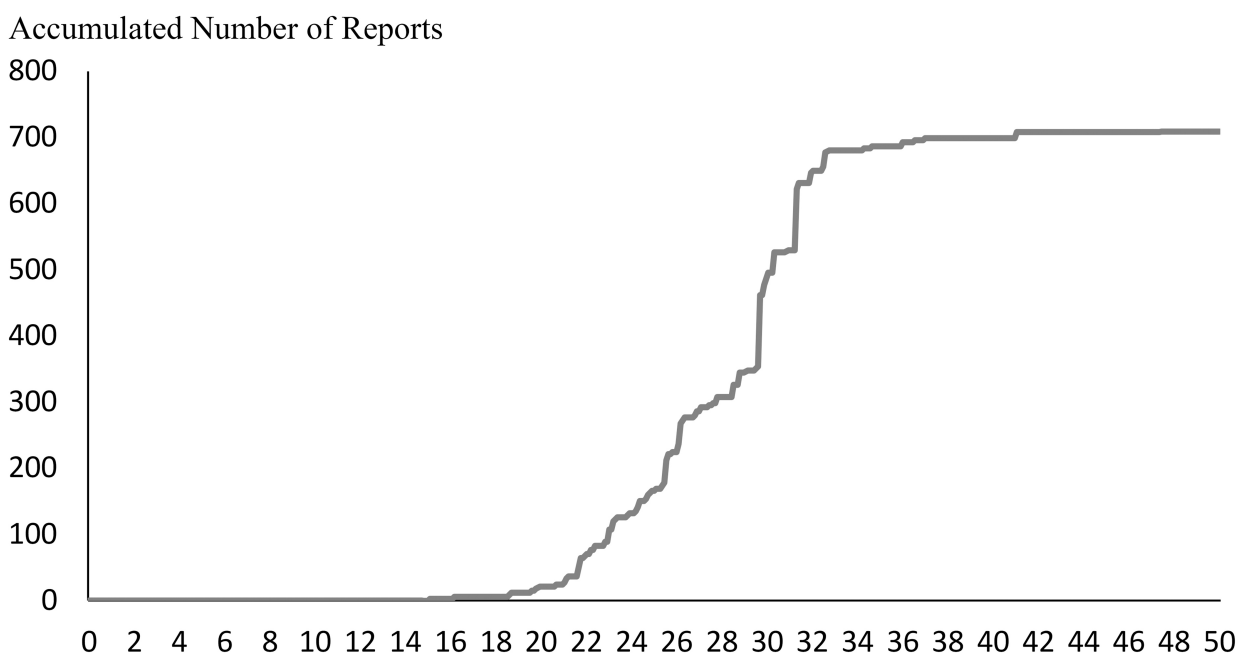

Sum of length, width and depth (0.1-mm increments)

Figure 3 Continuous graph of the accumulated number of reports. The $x$ axis represents the sum of the length, width, and depth of the tablets/capsules $(0.1-m m$ increments), whereas the $y$ axis represents the accumulated number of reports.

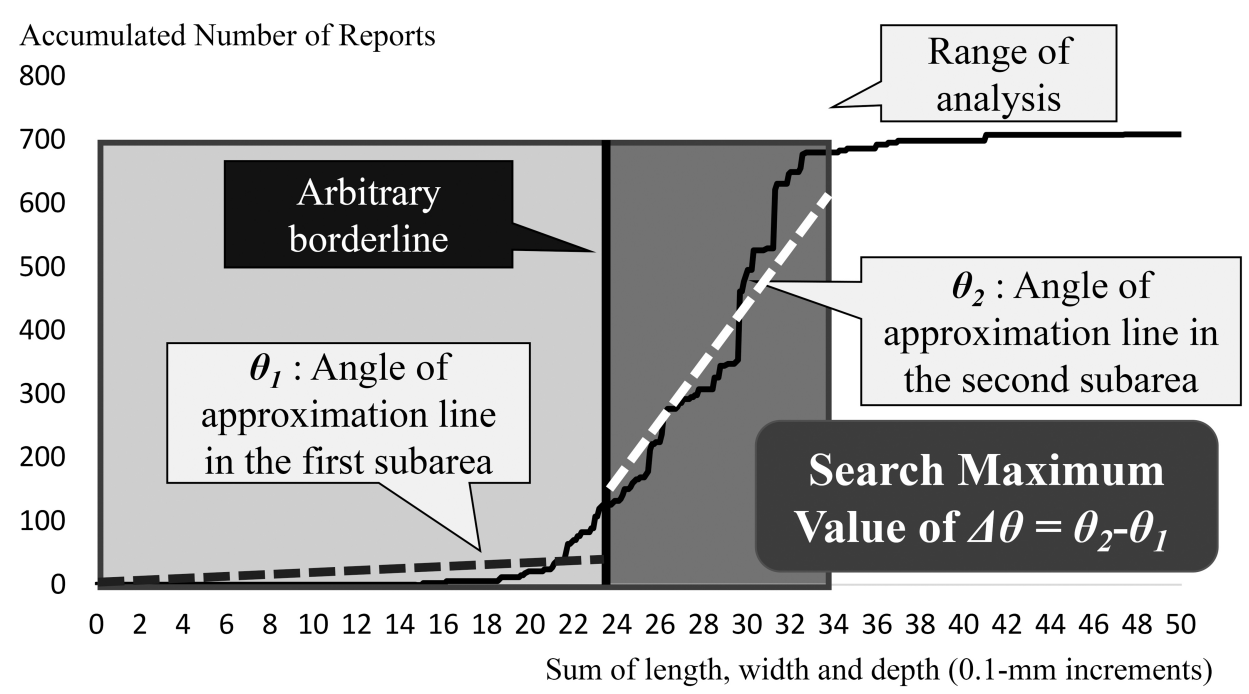

Figure 4 Geometric analysis with linear approximation for the accumulated number of reports. The $x$ axis represents the sum of the length, width, and depth of the medical tablets/capsules (0.1-mm increments), whereas the $y$ axis represents the accumulated number of reports.

1. The analysis range was defined as $0-33 \mathrm{~mm}$ at $I$, where the frequency of reports dropped

2. To consider the geometric angle, the analysis range (approximately $700 \times 33$ ) was revised to a square area

3. An arbitrary borderline was set to separate the entire area into two subareas

4. In each subarea, an approximation line of the graph was drawn and the coefficient was calculated

5. An inverse trigonometric function was applied to the coefficient and linear approximation angles $\left(\theta_{1}\right.$ and $\left.\theta_{2}\right)$ in the subareas were calculated
6. The difference between the two linear approximation angles was determined

7. By shifting the arbitrary borderline by $0.5-\mathrm{mm}$ increments, the borderline that maximized the difference in linear approximation angles was determined

In this analysis, the linear approximation angle of one subarea nears to the linear approximation angle of the other subarea, and the difference declines if the bending point in the graph is included in the area. Maximum difference implies that the borderline equals the bending point. Therefore, the calculated borderline that maximizes 
the difference in linear approximation angles is the bending point in the graph and can be considered as the threshold size of medical tablets/capsules for patients.

\section{Result}

\section{Analysis of Histograms}

Figure 5 shows the histograms of the six indices. The $x$ axes represent the calculated $I$ of each medical tablet/ capsule, and the $y$ axes represent the number of reports in the $I$ range. Three of the six indices were considered appropriate for medical tablet/capsule size: length $\left(I_{1}\right)$, length + width $\left(I_{2}\right)$, and length + width + depth $\left(I_{3}\right)$. As the other three indices, length $\mathrm{x}$ width $\left(I_{4}\right)$, length $\mathrm{x}$ width $\mathrm{x}$ depth $\left(I_{5}\right)$ and weight $\left(I_{6}\right)$, had wide and decentralized distribution, these were considered inappropriate to decide a threshold. After further observation, $I_{1}$ was found to be inappropriate because it could not distinguish round medical tablets/capsules from oval medical tablets/capsules and showed two peaks. In addition, $I_{3}$ was found to be better than $I_{2}$ because $I_{3}$ (the report increase ratio on the threshold was 14.7 times) had greater rise than $I_{2}$ (4.6 times) and considered more dimensions. Consequently, the histograms showed that $I_{3}$ was the most suitable index of medical tablet/capsule size.
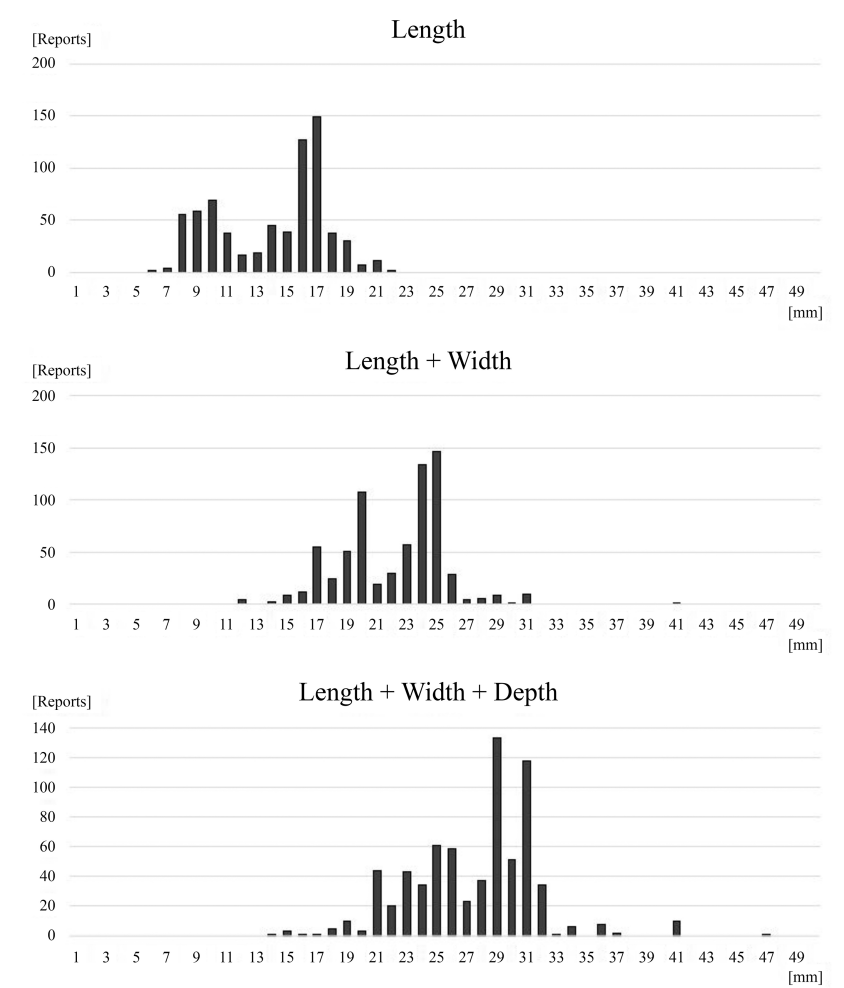

The $I_{3}$ histogram showedadrasticincrease innegativereports onmedical tablet/capsule size at a score of $21 \mathrm{~mm}$. Therefore, $I_{3}=$ $21 \mathrm{~mm}$ was considered the threshold size of medical tablets and capsulesthatpatientsfeelaretoolargetoingest.

Moreover, a control histogram (Figure 6) of 200 products that were used most frequently in Japan in 2014-2015 was constructed and compared with the $I_{3}$ histogram. ${ }^{18}$ The distributions of reported and frequently used medical tablets/capsules were different; the products reported with the size problem mainly exist between 21 and $32 \mathrm{~mm}$, while most of the frequently used products were distributed between 15 and $22 \mathrm{~mm}$, with the peak at $17 \mathrm{~mm}$. Therefore, we concluded that there is no or ignorable effect of the distribution of medical tablets/capsules on the increase in the number of reports at $I_{3}=21 \mathrm{~mm}$.

\section{Geometric Analysis with Linear Approximation}

To determine the bending point in the graph of $I_{3}$ and the accumulated number of reports, the arbitrary borderline was shifted and the difference between linear approximation angles $\left(\theta_{1}\right.$ and $\left.\theta_{2}\right)$ was determined. This difference between the two linear approximation angles was highest when the borderline was $21 \mathrm{~mm}$ (Figure 7).
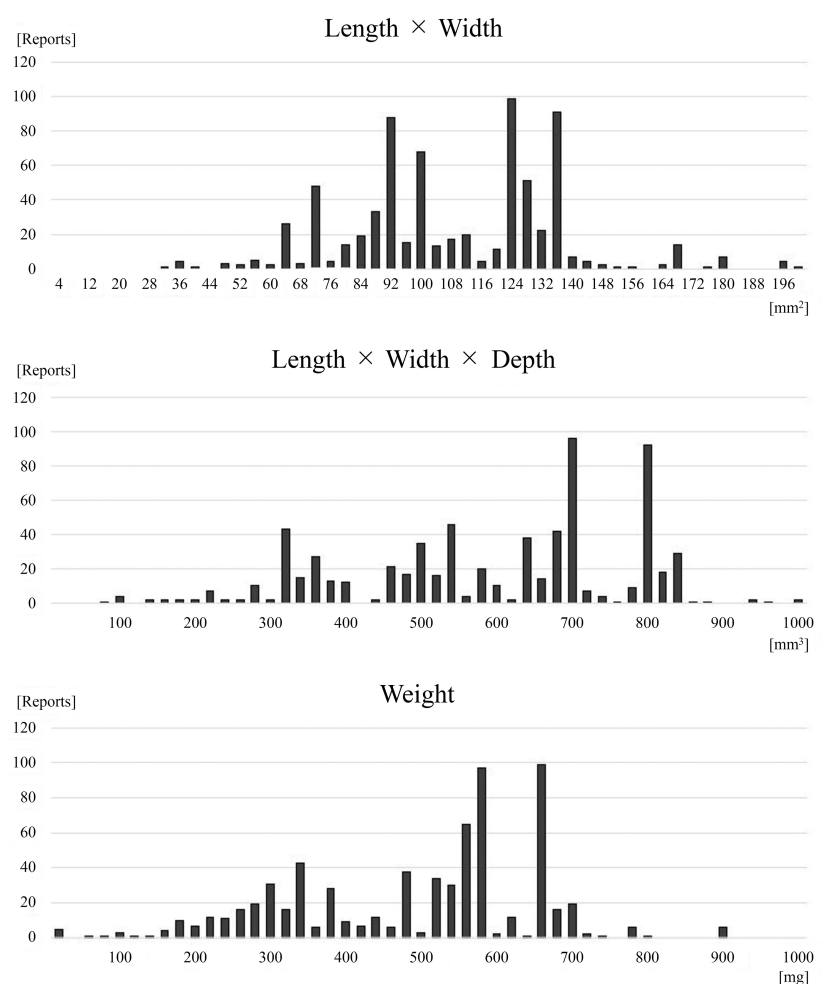

Figure 5 Six histograms of six indices of the size of medical tablets and capsules. The $x$ axis represents each index score. The width of each bin is I (histograms I-3), 4 (histogram 4), or 20 (histograms 5 and 6). The $y$ axis represents the number of reports. 

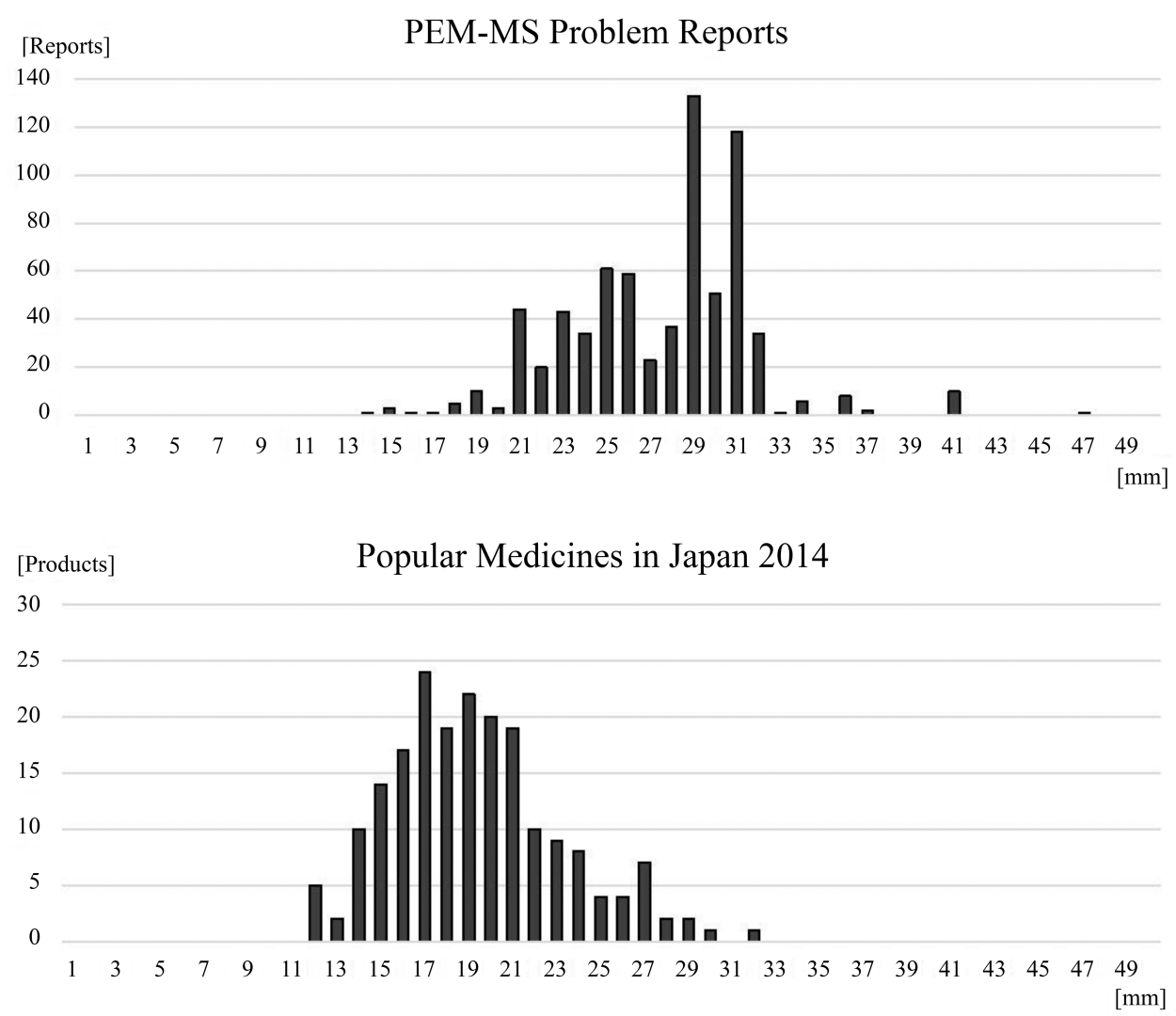

Figure 6 Histogram comparison between PEM-MS reports on problems and popular medical tablets/capsules in Japan. (Top): Distribution of problem reports in the PEM-MS system. (Bottom): Distribution of the 200 most popular medical tables/capsules in Japan in 2014-2015. The $x$ axis represents the sum of the length, width, and depth of the medical tablets/capsules. The width of each bin is $1 \mathrm{~mm}$. The $y$ axis represents the number of reports or products. PEM-MS, postmarketing event monitoring marketing specialists.

Therefore, similar to the histogram analysis, geometric analysis with linear approximation also indicated that $I_{3}=$ $21 \mathrm{~mm}$ is the threshold size of medical tablets and capsules that patients feel are too large to ingest.

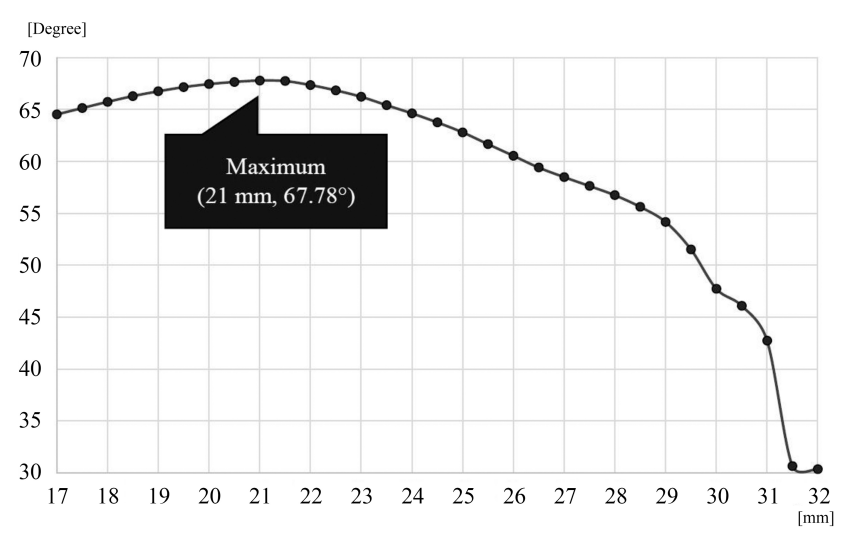

Figure 7 Difference between linear approximation angles in the arbitrary borderline. The difference between the two linear approximation angles was the highest when the borderline was $21 \mathrm{~mm}$. The $x$ axis represents the borderline value $(\mathrm{mm})$, whereas the $y$ axis represents the difference between linear approximation angles of approximation lines.

\section{Discussion}

In this study, the authors aimed to determine the upper threshold size of medical tablets and capsules for patients using histograms and geometric analyses with 709 reports collected by MSs of a medical wholesaler. The two analyses both suggested that $I_{3}=21 \mathrm{~mm}$ is the threshold size of medical tablets and capsules that patients feel are too large to ingest.

When designing or improving a drug in the form of a tablet/capsule, it is essential to take certain measures (eg, scoring, splitting into smaller doses, or redesigning as an orally disintegrating formulation) if $I_{3}$ of the medical tablet/capsule is $\geq 21 \mathrm{~mm}$. However, care should be taken and suitable options should be considered depending on the characteristics of the drug and the situation. Studies have shown that splitting a drug into smaller doses, thereby increasing the number, can be a burden on some patients. ${ }^{19}$ In addition, orally disintegrating tablets cannot always be helpful; they were already included in the problem reports in this study; they have stability problems, 
especially due to their hygroscopic nature, making it difficult to help patients using one-dose packages. ${ }^{20,21}$

As for $I_{1}$ (length), two peaks were observed in the histogram. Further investigation revealed that the first peak mainly included round medical tablets, while the second peak mainly consisted of oval medical tablets and capsules. Accordingly, histogram analysis showed that a diameter of $8 \mathrm{~mm}$ can also be the threshold size, as long as round medical tablets are concerned. This is consistent with some previous reports stating that a diameter of $7.0-7.9 \mathrm{~mm}$ is appropriate for round medical tablets. ${ }^{7,13}$

This study has some novelty and strengths. First, it used MSs of a medical wholesaler for postmarketing surveillance for collecting information and generated knowledge from it. In Japan, postmarketing surveillance is mainly operated by MRs of pharmaceutical companies. However, the MSs of medical wholesalers are considered as better information collectors than MRs because they deal with a wider range of medicines and visit medical institutions more frequently.

Second, a wide range of information was collected. Its great coverage and efficiency over community pharmacies enabled this study to consider a wide range of patient problems and requests, and to generalize the collected information to obtain universal knowledge.

The study also had some limitations. First, the information was collected only in Japan, especially Tokyo region. A previous study conducted in the United Kingdom suggested a threshold diameter of $13 \mathrm{~mm}$ for round tablets, ${ }^{11}$ implying regional differences. Therefore, similar studies in different regions of Japan and/or other countries could lead to differing and interesting conclusions. Incidentally, in October 2017, the PEM-MS system covered the entire Japan and is expected to collect and stock reports from regions other than Tokyo as well.

Second, this study did not consider the accurate volumes of drugs because exact data from pharmaceutical companies were not acquired or actual drugs were not assessed; however, the volume is relatively easy to check in the design process and worth considering.

Third, the PEM-MS system does not target detailed private information of patients; thus, we could not adjust the data based on the background data. Therefore, factors such as diseases or swallowing capabilities may influence the results of this study.

Finally, as mentioned before, the PEM-MS system was unable to collect large number of reports on medical tablet/ capsules that are too small; therefore, this study did not reveal the threshold size of medical tablets/capsules that patients feel are too small. In the future, the continuously operating the PEM-MS system will accumulate more reports on medical tablets/capsules that are too small. This will also help to assess the threshold size of such tablet/capsules, enabling the determination of both the upper and lower threshold size of medical tablets/capsules and further adding value to the knowledge gained from this study.

This study is a completely new endeavor aiming to generate pharmaceutical knowledge from information collected by MSs of a medical wholesaler. As the objectives were mostly achieved, this study was successful and contributed to the activities of medical wholesalers and their MSs. Although postmarketing surveillance by MSs has not sufficiently permeated medical institutions, which is critical, ${ }^{22}$ the accumulation of similar reports and collaboration between MSs and other medical workers will surely accelerate medical wholesalers' participation in postmarketing surveillance and realize a more sophisticated global pharmaceutical industry and more effective drug evolution and fostering.

\section{Conclusion}

$I_{3}$ is a suitable index of medical tablet/capsule size, and $I_{3}=$ $21 \mathrm{~mm}$ is the threshold size of medical tablet/capsules that patients feel are too large to ingest. In addition, for round tablets, a diameter of $8 \mathrm{~mm}$ is the threshold size. Medical tablets/capsules with $I_{3} \geq 21 \mathrm{~mm}$ are too large for patients to ingest. This study succeeded in obtaining useful pharmaceutical knowledge for drug formulation design and development from the postmarketing information collected by MSs of a medical wholesaler. Thus, postmarketing surveillance by MSs would continue to generate increasingly interesting and useful pharmaceutical knowledge.

\section{Abbreviations}

MRs, medical representatives; PEM-MS, postmarketing event monitoring marketing specialists; MSs, marketing specialists; $I_{1}$, length; $I_{2}$, length + width; $I_{3}$, length + width + depth.

\section{Acknowledgments}

The authors sincerely thank medical workers, marketing specialists, and people in Pharmaceutical Affairs Department of Toho Pharmaceutical Co., Ltd. for their contribution to the postmarketing surveillance in this study.

Also, the authors would like to thank Enago for the English language review. 


\section{Funding}

This research did not receive any specific grant from funding agencies in the public, commercial, or not-forprofit sectors.

\section{Disclosure}

Kenji Kabeya has nothing to disclose. Hiroki Satoh reports that this work was conducted as a joint research with Toho Holdings Co., Ltd., during the conduct of the study; that the Laboratory of Drug Lifetime Management was funded by 11 companies including Toho Holdings Co., Ltd., and personal fees from Torii Pharmaceutical Co., Ltd., and neopharma Japan Co., Ltd., outside the submitted work. Yasumasa Miura reports personal fees from Toho Holdings Co., Ltd., outside the submitted work. Satoko Hori was a member of the Laboratory of Drug Lifetime Management funded by 11 companies including Toho Holdings Co., Ltd., during the early part of this work. Yasufumi Sawada reports that this work was conducted as a joint study with Toho Holdings Co., Ltd., during the conduct of the study; and that the Laboratory of Drug Lifetime Management was funded by 11 companies including Toho Holdings Co., Ltd., outside the submitted work. The authors report no other possible conflicts of interest in this work.

\section{References}

1. Tsushima Y. Medical tablets easy to ingest: development of new drug formulation toward aging society. Farumashia. 1997;33(10):11191123. doi:10.14894/faruawpsj.33.10_1119

2. Imai Y. Home drug management and care cost for the elderly with dementia. $J$ Ther. 2005;87(2):433-442.

3. Kurata N, Enomoto A, Kato H, Kataoka S. Medicines that are appropriate for elderly persons-evaluation of the size of oral disintegrating tablets that can be ingested. Jpn J Pharm Health Care Sci. 2010;36 (6):397-405. doi:10.5649/jjphcs.36.397

4. Sato H, Saito S, Hayashi T. Shape of tablets for ease of swallowing. Trans Jpn Soc Kansei Eng. 2010;9(2):137-143. doi:10.5057/jjske.J11090515-1

5. Sato H, Saito S, Ikeda M. Shape of tablets for ease of swallowing by senior citizens. Trans Jpn Soc Kansei Eng. 2011;10(3):417-423. doi:10.5057/jjske.10.417

6. Miura H, Kariyasu M. Effect of size of tablets on easiness of swallowing and handling among the frail elderly. Jpn J Geriatr. 2007;44 (5):627-633. doi:10.3143/geriatrics.44.627
7. Oshima T, Hori S, Maida C, Miyamoto E. Effect of size and shape of tablets and capsules on ease of grasping and swallowing (1): comparison between elderly and students. Jpn J Pharm Health Care Sci. 2006;32(8):842-848. doi:10.5649/jjphcs.32.842

8. Goto H, Ogata H. Effect of the size of dosage forms on easiness of swallowing in healthy subjects and inpatients. Yakuzaigaku. 1990;50 (3):230-238.

9. Miura H, Kariyasu M. Relationship between the size of tablets and subjective evaluation on easiness of taking medicine. Jpn J Med Pharm Sci. 2007;57(6):829-834.

10. Hashimoto T. Survey on medication compliance and awareness of dosage form in elderly patients. Ther Res. 2006;27(6):1219-1225.

11. Ranmal SR, Cram A, Tuleu C. Age-appropriate and acceptable paediatric dosage forms: insights into end-user perceptions, preferences and practices from the children's acceptability of oral formulations (CALF) study. Int J Pharm. 2016;514(1):296-307. doi:10.1016/j. ijpharm.2016.07.054

12. Sugihara M, Hidaka M, Saito A. Discriminatory features of dosage form and package. J pn J Hosp Pharm. 1986;12(4):322-328. doi:10.5649/jjphcs 1975.12 .322

13. Sugihara M, Awazu S, Ueda K, et al. Silver Science Study, Showa 62th Study Report. Tokyo: Ministry of Health and Welfare; 1988.

14. MR Education and Accreditation Center of Japan. MR circumstances investigation: the investigation on the image of MR playing a part in medical care. Available from: https://www.mre.or.jp/info/guideline. html\#guideline09. Accessed Mar 14, 2018.

15. Sawada Y, Satoh H, Asano T et al. Abstracts of papers. The 25th Annual Meeting of the Japanese Society of Pharmaceutical Health Care and Sciences; November; 2015; Yokohama. 230.

16. Sadamatsu N. Drug information and pharmacovigilance: from the viewpoint of a medical wholesaler. Jpn J Drug Inform. 2006;8 (1):72-78.

17. Okamato S. Medical supply information activity of wholesalers. Pharm Lib Bull. 2001;46(3):240-247. doi:10.11291/jpla1956.46.240

18. Ministry of Health, Labour and Welfare. 1st NDB open data. Available from: https://www.mhlw.go.jp/stf/seisakunitsuite/bunya/ 0000139390.html. Accessed Nov 11, 2016.

19. Yano K, Itoda Y, Arakawa H, Inoue T, Ogihara T. A comparative examination of two pre-existing tablets and one double sized tablet from the view of both recipient and pharmacist. Jpn Pharmacol Ther. 2015;43(2):165-173.

20. Namiki N, Negishi T, Katou J, Kaneko M, Sakakura M. Studies on the application of oral rapid disintegrating tablets using a fully automatic tablet packing machine. Jpn J Pharm Health Care Sci. 2003;29 (3):367-374. doi:10.5649/jjphcs.29.367

21. Otori K, Nishio T, Taguchi Y, Kaji E, Yago K. Evaluation of the longterm stability and sensory properties of orodispersible famotidine tablets. J Jpn Soc Hosp Pharm. 2008;44(8):1259-1263.

22. Kabeya K, Sato H, Hori S, Miki A, Miura Y, Sawada Y. Problems and solutions on post-marketing surveillance by marketing specialists: outcomes of the workshop using KJ method. Jpn J Drug Inform. 2019;21(2):49-56. doi:10.11256/jjdi.21.49
Patient Preference and Adherence

\section{Publish your work in this journal}

Patient Preference and Adherence is an international, peer-reviewed, open access journal that focuses on the growing importance of patient preference and adherence throughout the therapeutic continuum. Patient satisfaction, acceptability, quality of life, compliance, persistence and their role in developing new therapeutic modalities and compounds to optimize clinical outcomes for existing disease states are major areas of interest for the journal. This journal has been accepted for indexing on PubMed Central. The manuscript management system is completely online and includes a very quick and fair peer-review system, which is all easy to use. Visit http:// www.dovepress.com/testimonials.php to read real quotes from published authors. 